\title{
Pedagogy and Overview of a Graduate Program in Digital Investigation Management
}

\author{
Gary C. Kessler ${ }^{1}$ \\ Center for Digital Investigation \\ gary.kessler@champlain.edu \\ Don Haggerty \\ Division of Information Technology \& Sciences \\ haggerty@champlain.edu \\ Champlain College \\ Burlington, Vermont, U.S.A.
}

\begin{abstract}
Although still a relatively new undergraduate course of study at most colleges and universities, specialized degree programs in computer forensics and digital investigations are now becoming available at the graduate level. There appear to be two divergent educational paths for graduate-level education in this field, namely, technology and management. This paper describes Champlain College's online Master's degree program in Digital Investigation Management. The proposed curriculum is described, along with the learning theories and pedagogies that provide the guiding principles for course design. Issues related to the online learning environment and adult learners are also presented.
\end{abstract}

\section{Introduction}

Although an increasing number of colleges and universities around the globe have started to offer programs in computer forensics and digital investigations, this is still a relatively new discipline in undergraduate education. Interestingly, while most of the programs were developed largely in response to requirements of the law enforcement community and to fill the needs reported in several national studies $[1,2$, $3]$, most of the growing needs for this skill set come from private sector organizations providing data recovery, electronic discovery (e-discovery), incident response, policy auditing, and third-party forensic analysis services.

\footnotetext{
${ }^{1}$ Adjunct Associate Professor, School of Computer and Information Science, Edith Cowan University, Mount Lawley, Western Australia.
}

As the discipline matures, the educational needs have come into sharper focus and several guidelines have started to appear $[4,5]$. The need for the nextgeneration of leaders has also resulted in the need for advanced, graduate-level education in digital forensics, and definitions $[4,5]$ and actual programs $[6,7]$ are already being offered. The graduate proposals to date, however, are largely steeped in technology and computer science, preparing students for more rigorous research and development in the technical problems related to computer forensics, such as the need for more and better examination and reporting tools, coping with whole disk encryption, acquiring data from cellular telephones and other mobile devices, and combating anti-forensics tools. Graduates from these technical graduate programs are those that will be designing next generation computer forensics analysis tools, techniques, and processes.

Champlain College's Computer \& Digital Forensics (C\&DF) undergraduate degree and academic certificate programs started in 2003 and have been previously described $[8,9]$. As the college reviewed the need for graduate education, it was found that another critical need in digital forensics was not being addressed by advanced education -- namely, management issues related to overseeing large cases, running computer forensics labs, hiring staff, conducting research, etc.

Section 2 of this paper will discuss a proposed graduate degree program in Digital Investigation Management (DIM). Section 3 will present the pedagogic issues related to this program designed for adult students with experience in the field. Section 4 will provide some concluding comments. 


\section{The M.S. DIM curriculum}

This section will describe the M.S. degree program in Digital Investigation Management. The first part will present some of the philosophical underpinnings of the program and the second part will describe the individual courses.

\subsection{Curriculum philosophy}

In 2002, Champlain College recognized a national and global lack of sufficient computer forensics professionals and responded with an undergraduate degree program to educate professionals in this growing field; the program started on campus in 2003 and has been offered online since 2004. Since that time, the college has focused on the undergraduate curriculum and the requirements for a B.S. degree in this field.

One of the seminal papers that convinced the original curriculum designers that such a program was necessary identified ten critical issues for local and state law enforcement with respect to computer crime [3]: public awareness, data reporting, uniform training and certification, management assistance for on-site electronic crime task forces, updated laws, cooperation with high-tech industry, special research and publications, management awareness and support, investigative and forensics tools, and structuring a computer crime unit. By 2006, discussions with colleagues and practitioners in both the private and public sectors suggested that most of these critical issues remain open or, at least, inadequately addressed [10].

Most of the open issues, however, are not just about technology or personnel. In fact, all of these issues can be addressed and, to a large part, resolved through appropriate long-term management and policy creation. But just as computer forensics and digital investigations require specialized training and education, the management necessary to address these issues is also specialized. Most individuals running electronic or high-tech crime units, however, are law enforcement officials who have risen through the ranks of law enforcement as digital investigators but who, largely, do not have this type of specialized management training. Private sector digital evidence practices are also staffed by a large number of former law enforcement computer forensics examiners.

Discussions with our undergraduate students (many of whom are already experienced examiners), outside practitioners, organizations hiring computer forensics examiners, potential students, other industry experts and academics, and our program's Advisory Board convinced the program designers that the lack of a management focus on computer forensics was a growing gap in the field in both the private and public sector. In addition, a management perspective is ideally suited to graduate level education; indeed, many examiners noted that their path for career advancement was best served by obtaining an advanced degree that would enable them to move into a management role.

Champlain College already has Masters in Business Administration (MBA) and M.S. in Managing Innovation and Information Technology (MIIT) degree programs. The synergies realized by coupling the experience with our undergraduate C\&DF program and our graduate management programs made the offering of a graduate management degree in computer forensics seem like a natural next step.

Table 1: M.S. DIM Curriculum

\begin{tabular}{|c|c|c|}
\hline $\begin{array}{l}\text { Course } \\
\text { Number }\end{array}$ & Course Name & $\mathrm{Cr}$. \\
\hline MBA 500 & Integrated and Reflective Practice ${ }^{1}$ & 1 \\
\hline DIM 500 & Practice of Digital Investigations ${ }^{1,2}$ & 3 \\
\hline MBA 525 & Process Improvement and Operations & 3 \\
\hline MIT 505 & Project Management & 3 \\
\hline MIT 525 & Financial Decision Making for Mgmt. & 3 \\
\hline MIT 530 & IT Security and Strategy & 3 \\
\hline MIT 550 & Reflective Leadership \& Planned Change & 3 \\
\hline DIM 530 & Legal Aspects of Digital Investigations ${ }^{2}$ & 3 \\
\hline DIM 540 & Current Topics in Dig. Inv. Techniques ${ }^{2}$ & 3 \\
\hline DIM 550 & Laboratory Operation and Accreditation ${ }^{2}$ & 3 \\
\hline DIM 570 & Research Methodology & 3 \\
\hline DIM 580 & Legal Issues for Management & 3 \\
\hline DIM 590 & Integrative Capstone Project ${ }^{3}$ & 3 \\
\hline
\end{tabular}

Notes:

1) DIM 500 and MBA 500 are first-term courses.

2) DIM 500, 530, 540, and 550 comprise the grad. certificate.

3) DIM 590 is a last-term course.

\subsection{M.S. DIM courses}

The M.S. DIM curriculum is a 37 -credit course of study, comprising 12 three-credit courses plus a single one-credit course. Six of these courses are taken from the existing MBA and MIIT programs, and provide breadth to the M.S. DIM management study. The remaining seven courses were developed for this program, although several could be used in other programs. A 12-credit graduate level certificate in Digital Investigation Process Management has also been defined. The curriculum is summarized in Table 1 and the courses are described in more detail in the paragraphs below. 
- Integrated and Reflective Practice (MBA 500): A first-term course that provides the basis of both the philosophy and the professional development perspective used in all subsequent courses. Students complete a thorough and multidimensional self-assessment that culminates in a personal learning roadmap to guide their journey through the entire graduate program. The emphasis of the content is on the importance of work-practice and experience as a basis for management development and on the use of experience for personal and organizational learning. Specific topic areas include learning style, action learning, dialogue, communication, personality type, and team communication. Short case studies will also address the integration of learning through several areas of practice. This course sets the stage for subsequent courses that are grounded in an experientially-based learning process while introducing the integrated content areas. (Integrated and reflective practice is a fundamental pedagogy for the program and described in more detail in Section 3.1.)

- The Practice of Digital Investigations (DIM 500): The foundation for this program of study, this course introduces the principles that are essential to the management of digital investigations, providing a framework that includes technical, legal, and managerial issues. Students will examine the mission of digital investigations from the various perspectives of the public and private sectors, including digital forensics in support of activities ranging from internal corporate investigations, responses to information security incidents, and policy auditing to third-party investigations, criminal investigations, and anti-terrorism information gathering -- and discussing the imperatives of each. As relevant, the impact of international and cultural issues, as well as geopolitics will be an essential part of class discussion. A moral, ethical, and legal framework will also be explored and developed, which can be used as a template for future courses. The capacity to make decisions based on organizational and personal values with which to pursue organizational goals will be explored.

- Process Improvement and Operations (MBA 525): This course approaches an organization's operations and processes from both the initial design and continuous improvement perspective. Students will develop the ability to define, design and improve business processes; something now considered to be one of the most frequently cited skills for today's workplace. Special attention will be given to the linkage between operational and process improvement metrics to those based upon financial, economic and accounting information. This linkage cannot be overemphasized as skills developed in this course provide a foundation for economic modeling and planning. The sum of this will help define models of broad and optimized organizational performance measures such as scorecard type approaches. Among the areas of practice included are the governance of financial resources, the innovative use of operational data and the economics of improvement programs.

- Project Management (MIT 505): This course is designed to introduce a systematic process for planning, organizing and controlling projects based on a practical methodology for completing projects more quickly with fewer problems. Students will develop and apply a framework within which to: better manage projects, exercise both hard and soft project management skills and affect organizational culture toward acceptance of project management. Areas of emphasis include an array of principles, methods, tools and techniques that can be applied to any type or size of project and in any organization. Course content is aligned with the Project Management Institute (PMI) processes and knowledge areas but will center on the process of project management. The course provides a perspective that is integrative, first, through its concept of end-to-end thinking which will be applied to the project management processes and, as well, to the business processes of a project's clients. Areas of practice addressed include the measurement and improvement of processes, the application to customer and marketing management and financial decision making.

- Financial Decision Making for Management (MIT 525): This course is an introduction to the basic financial principles and tools required for organizational management. Students will develop the ability to respond to the concerns and motivations of the financial community or financial stakeholders which are important constituencies of any enterprise that ultimately impact the flow of money to every organization. Specific emphasis will be placed on the topics of understanding costs, the time value of money, economic analysis techniques, and methods of evaluating business proposals. The intent is to provide the learner with a "tool box" of practical, useful personal tools that will support the decision making process when business projects are being 
assessed. The course integrates well with the areas of practice that include performance measurement, process improvement and the need to be innovative in the application of financial techniques.

- IT Security and Management (MIT 530): The security of information and information systems is inextricably linked to the operation and assets of any organization. Protecting the information network infrastructure is essential to protecting our businesses and organizations. This course provides the essentials of IT security from a management perspective. It examines the processes of security, including information assurance, privacy, backup and recovery, and disaster preparedness. This course provides an overview of information security processes for managers. Students will examine methodologies for implementing security, security policies, best current practices, privacy, backup/recovery, disaster preparedness and incident response. The outcome of this process is a strategic security plan.

- Reflective Leadership and Planned Change (MIT 550): This course addresses the complexity and changing nature of business environments that challenge organizations and their members to become adaptive and innovative. This course is an introduction to a variety of leadership models and to the emerging role of all managers as agents of change. Students will develop the knowledge and skills for harnessing, navigating and leading change in their respective organizations; they will reflect on their experiences as a leader and assess who they are as a leader based on the models presented and used in the course. Areas of emphasis include personal leadership philosophy; change as an ongoing and dynamic process owned by everyone in the organization and the emergence of change leaders. Special attention will be given to change as a process that impacts people, affects organizational relationships, is driven by financial/market forces, and needs to be measured in terms of organizational results. Among the areas of practice addressed are human resources and organizational relationships, financial and operational results, the need to understand market driven changes and the role of values as evidenced by the organizational culture.

- Legal Aspects of Digital Investigations (DIM 530): This course discusses advanced legal issues related to the seizure of digital devices. The course will review such laws as the Computer Fraud and Abuse Act (CFA), Electronic Communication Privacy Act (ECPA), and Privacy Protection Act
(PPA), with particular attention paid to evolving decisional law surrounding the Fourth Amendment and device devices. Liaison to other agencies, law of other countries, and international laws will also be examined. Issues related to trial preparation, presentation of digital evidence, use of expert witnesses, and providing testimony will be examined in detail. Special attention will be paid to jurisdictional differences related to digital investigations and cybercrime, particularly as they relate to rules of evidence; e.g., Federal Rules of Evidence (FRE) compared with the different state standards based on Frye, Daubert, or other criteria. Students for this course will be expected to have basic familiarity with criminal law and procedure.

- Current Topics in Digital Investigation Techniques (DIM 540): This course examines advanced computer and network forensics issues, techniques, and procedures. Topics will include mobile device forensics (cell phones, PDAs, MP3 players, etc.), examination of network devices, current research topics in digital forensics, and best practices in digital investigations.

- Laboratory Operation and Accreditation (DIM 550): This course discusses practices and issues related to the management of a computer forensics lab for either the public or private sector. Topics will include best practices in lab operation, case management, and evidence management and storage, maintaining proficiency, personnel training and certification, and development of policies and procedures. Accreditation from organizations such as the American Society of Crime Laboratory Directors (ASCLD) and compliance with standards such as ISO 17025 will be discussed, including the pros and cons, cost, and process of compliance, impact on employees and processes, etc.

- $\quad$ Research Methodology (DIM 570): This course provides an overview of the research process from the experimental, developmental, and evaluative perspectives. Techniques for planning and designing these different types of projects as well as the methodologies for data collection, evaluation, and analysis are examined. Students will gain an understanding of related statistical measures. The development of conclusions based on the data analysis in terms of predefined hypotheses and/or project goals and objectives will also be discussed.

- Legal Issues for Management (DIM 580): This course will address the legal -- and ethical -- issues related to operating public and private sector organizations. Topics will include public and 
private sector labor law, regulations and policies governing personal information, as well as personnel, medical, financial, and other records (e.g., Family Educational Rights and Privacy Act [FERPA], Gramm-Leach-Biley, Health Insurance Portability and Accountability Act [HIPAA], and Sarbanes-Oxley [SOX]), applying for and administering grants from public and private sources, and reporting and neutrality requirements. Human resource issues related to hiring and managing employees and consultants will also be covered.

- Integrative Capstone Project (DIM 590): This course will provide students with the opportunity to integrate all disciplines and competencies that have been learned in this program into a single work-based project, internship experience, or other appropriate activity. The project will be the culmination of a student's studies integrated in their area of specialization or expertise. In cooperation with an advisor, the student will design, research, and implement a project that is comprehensive in nature and which addresses, to the extent feasible, all core areas of knowledge around which the program has been built.

The courses above can be taken in more-or-less any order as there is no strict prerequisite structure. The only exceptions are that students start with foundation courses, MBA 500 and DIM 500, and culminate with the capstone course (DIM 590). The graduate certificate focusing on managing the digital investigation process is composed of DIM 500, 530, 540 , and 550.

\section{Program pedagogy}

The M.S. DIM program was specifically designed to be offered online to adult learners who are currently digital forensics practitioners. This section will describe Integrated Reflective Practice (IRP), the pedagogic foundation of the program. Other online course pedagogies and issues specific to adult learners have already been described in [8] and are only briefly reviewed here. This section will also briefly present some of the generic issues related to online learning environments (OLEs); although the college uses the WebCT learning management system (LMS), this paper will not present a critique of the product.

\subsection{Integrated Reflective Practice}

The DIM program is built on the pedagogical foundation of Champlain's unique learning model called Integrated Reflective Practice. IRP emerges from the discipline of workplace learning which is, by definition, learning from experience. Through workplace learning, IRP's roots draws on the learning theories of Dewey, Lewin, and Piaget, including Dewey's observation that learning is a dialectic process integrating social aspects, experience, and abstractions $[11,12,13]$.

Integrated learning occurs at two levels; through selected interdisciplinary activities that link core content courses and assignments that require integrating classroom theory to the workplace. The interdisciplinary nature is created through a whole picture perspective in which five areas of practice are used repeatedly throughout the program's courses: measurement and process improvement, innovation through information, financial and economic resources, human resources and organizational relationships, and customers and marketing.

Courses are also integrated with the workplace through action learning projects in which students learn from real problems and develop an understanding of the linkages between theory and practice. Projects comprise a significant portion of each student's time spent and their assessment, typically involve stakeholders in the workplace and provide one of the primary vehicles for reflection before, during and after their development [14].

Learning is reflective because personal reflection is required in every class as a means of students capturing new knowledge from their own experiences. Reflection is the nexus of experiential learning in the workplace and provides a foundation for true lifelong learning. Reflective, or double-loop, learning leads to improved performance and new knowledge about practice [15].

Learning theorists have long held that reflection is not necessarily a solitary activity and can best include others [16]. Reflection, then, includes aspects of collaborative learning where teams work together to solve problems $[17,18]$. Public reflection such as that used in online and real-time discussion groups is a cornerstone to all DIM courses [19].

Learning is linked to practice through both course content and the learning process. Project-based learning has immediate appeal to students because they are dealing with a real problem in a very concrete way. If the project deliverable is modeled after those seen in the workplace then the learning has the added benefit of providing valuable career education as well. In the case of the DIM program, the ongoing stream of projects provides several points at which the student needs to investigate a problem in the workplace and deal with the uncertainties of vaguely understood issues, loosely defined problems and incomplete data. Taken together, the set of projects completed in the 
DIM program will provide a portfolio of real work that provides students with a sense of self-confidence about their ability to start with nothing and finish with a work product that they can be proud of.

It is the consistency in the use of integration and reflection along with a practitioner orientation that is unique to the IRP learning model $[14,20]$.

\subsection{Online course pedagogy}

Quality online courses require quality content, course design, and material presentation. Proper educational pedagogies support the production of these materials as well as the IRP model. In the absence of a single Unified Theory of Learning, the DIM program employs a variety of teaching pedagogies to reach a wide variety of students with different learning preferences, attempting to employ the best characteristics of each pedagogic model where the online environment could leverage the greatest advantage [21, 22]. As suggested above, all of the learning theories used are based on Dewey's active learning model, which enhances student performance, improves their general attitude towards the course and material, and helps to create a sense of community among students and faculty $[13,23,24]$.

Five pedagogic models provide the main guidelines for the design of the master's degree courses. The first is social constructivism, Piaget's theory that cognitive structures are the building blocks of learning and extended by Dewey and Vygotsky who observed that learning is a social activity. Constructivism suggests that students create new knowledge based upon what they already know; students' mental organization skills need to be honed so that they learn new cognitive structures and how to build the linkages between them $[13,25,26]$.

An OLE is well-suited to constructivism if the technology supports the tools of social discourse, such as e-mail, discussion forums, white boards, and text messaging and voice conferencing facilities. Because of the lack of the social activity that would normally be found in an on-campus classroom, online instructors must be diligent and maintain what socialization is possible using the tools at hand. Because students can view lectures at their own pace and as many times as necessary, they also feel more free to communicate with the instructor and other students at any time during the week.

The second model is resource-based learning $(R B L)$. The Internet is today's equivalent of the Library of Alexandria in terms of the availability of resource material on every subject imaginable -- in both refined and unrefined form. Unlike the Library of Alexandria, of course, the Internet does not contain all known knowledge as many students believe; there is a lot of information -- and history -- that pre-dates the Internet and has not yet been digitized. Nevertheless, there is clearly an unprecedented volume of current and new knowledge accessible via the World Wide Web, and the acceleration of the addition of new information on the Web is overwhelming. The timeliness of Webbased information means that presentations and discussions can be based upon what is known at the moment rather what was known at the beginning of the course term. Students, too, can look up items of information to augment any lecture and do homework research -- and keep instructors on their toes. RBL also provides the instructor with the opportunity to give students more interesting and relevant assignments, projects, and tests.

The acceleration of change in the digital forensics field makes the almost limitless technical reference library of the Internet and online knowledge bases essential for graduate students, reminding the authors of this story about Albert Einstein (however apocryphal it might be): During the 1940s, Einstein once handed his secretary an exam to be distributed to his graduate physics students. The secretary looked at the paper and said, "Professor Einstein, these are the same questions that you used last year. Won't the students already know the answers?" "It's all right," replied Einstein, "You see, the questions are the same as last year, but this year's answers are different." The Internet and online resources can accommodate a wide variety of learning preferences and teaching styles, allow for the presentation of a number of views about an issue (requiring that students be instructed about how to apply critical thinking to the information they acquire), encourage students' curiosity and investigative skills, and engage students in active learning [22].

The third pedagogic model is collaborative learning, as suggested above. Group exercises teach team-building and communication skills, and demonstrate the synergy that a group brings to problem solving. Students also gain a more thorough understanding of the subject matter as they promote and defend their views while hearing other peoples' ideas. Students also learn about roles and negotiation. The OLE technology tools that support social constructivism also support collaboration and group exercises [13, 24, 27].

Problem-based, or project-based, learning (PBL) is the fourth model integrated into the DIM curriculum design. Real, relevant, and tangible problems generally motivate students more than contrived assignments. Students will generally make real-world assumptions that come from their own environments in order to 
solve these problems, adding further relevance as they hone their problem solving skills. PBL is well-suited to constructivism because students apply what they know to fully define the problem and find one of what may be many solutions to the stated problem; it is also wellsuited to the online environment because bigger, more interesting problems can be devised -- and solved using collaboration and the Internet as an information resource $[27,28]$.

The final pedagogic model is narrative-based teaching (NBT), which is to teach by telling stories or sharing experiences. Digital forensics benefits from narration and real-life "war stories" from instructors and students alike due to the rapid changes in technology, regulation, and the law, coupled with the fact that every investigation is different. NBT provides a glimpse into the very real practical, technical, and ethical issues that arise every day in the field. Narration fits well in an online course because media tools such as audio, video, and animation can enable -and enhance -- the story-telling. Providing a personal, real world context helps make a subject more memorable, interesting, fun, and engaging [22].

\subsection{The online learning environment}

Online courses provide students with access to educational opportunities that might otherwise be locked out due to their work or family schedule, geographic location, or other reasons. Champlain College's online courses provide an asynchronous, virtual classroom complete with an instructor, fellow students, syllabus, course assignments, projects -- and rigor. Graduate courses are taught in 10-week terms so that four terms can be presented each year; students typically take one or two courses per term.

Because of the key role that communication plays in the curriculum pedagogy, LMS and adjunct technology must provide a variety of communication and collaboration tools, including a threaded discussion capability that allow students to post comments for the entire class (or group) as well as an e-mail facility that allows message exchange between a student and the instructor, or between students. Text messaging, voice and video conferencing, and shared whiteboard facilities support real-time (synchronous) class or group meetings.

In some ways, the online virtual classroom has some distinct advantages over the traditional classroom for graduate courses. First and foremost, the online environment can allow more students to get involved in more class discussions because of its asynchronous nature. Some students are not active in classroom discussions for a variety of reasons, including not always having a well-reasoned comment to add. In the online classroom, students have time to think and create their response to the comments of others, and have time to post a response hours or days after the original comment was made. In fact, most online instructors require some level of participation in discussion so that all students are involved and engaged in the class, something that may not happen as often in an on-campus class. This additional time to synthesize the material and discussions further reinforces public reflection and social constructivism.

Finally, other features allow the power of the Internet to be integrated into the course. A list of Internet, college library, and other online resources, for example, can be built in to the course so that students can access tutorial and other adjunct materials. Remedial background information can be made available within the online class via links to tutorials and a student-run peer-tutoring service. Technical difficulties can be addressed via an online (and telephone accessible) helpdesk. All in all, there are many features to make the online classroom a complete learning experience.

\subsection{Online courses and the adult learner}

Champlain College's online graduate courses are specifically designed for adult learners, who are generally more mature and self-directed than traditional-aged students. Adult learners are best served with active, PBL methods, as suggested above. Essential course design elements include clearly-stated goals and objectives, learning modules that are as small as possible, and as high a level of interactivity between the instructor and other students as possible. Students are also advised up-front about the time expectations for the course as a whole, as well as per-assignment, to eliminate surprises that could deter success [22].

It is important that online courses be as technologytransparent as possible. Online courses should be developed so that content and other features are accessible by students employing a wide range of Web browsers, operating systems, or types of Internet connection, and technology requirements must be made known to the students prior to the beginning of the course. Course developers balance the computer power and network bandwidth required for each course so that it best suits the material to be delivered (e.g., HTML pages, streaming video, graphical image, audio, etc.) and the likely capabilities of the students, so as to assure the widest possible audience; an animation, for example, would better be delivered using Flash, a commonly-available browser plug-in, rather than a proprietary application that is browser-specific. A high 
level of computer sophistication should not be a requirement for online courses and good technical support must be readily available to students to reduce frustration and ensure that they do not feel cast adrift $[22,29,30,31]$.

The bottom-line is that the OLE needs to emphasize content rather than technology and the technology should enable rather than inhibit the learning experience. Indeed, quality of content is king; excellent technology cannot save poor content although poor technology can prevent access to excellent content. The online course Web site itself should be aesthetically pleasing and ergonomically sound. In addition to being attractive, the information on the site needs to be up-to-date and the pages easy to navigate -and even entertaining. The content needs to be wellwritten and relevant, and use vernacular that is familiar to the audience; the perception of a site being boring, poorly organized, or confusing can have a devastating effect on the students taking the course. The site doesn't need to be technologically fancy, however; simple HTML pages, text, and e-mail can be quite effective; students actually find it more important to be able to read a lecture and have the flexibility to set their own pace and time of study than to be able to hear a lecture and have face-to-face contact with the instructor and fellow students [22, 32, 33].

\subsection{Conclusion}

The concepts offered in this section provide an overriding guide for the development of online courses in the graduate DIM program. The pedagogic background shows that online courses are not merely online correspondence courses, but designed based upon well-founded learning theories.

Course development teams are responsible for the creation and review of all DIM courses. At the heart of the content preparation is a subject matter expert (SME). The SME may not have particular expertise in education or technology; the instructional technologists on the team work closely with the SME to find and develop appropriate media, assignments, delivery modes, and other items necessary to facilitate the online classroom. One advantage of online courses is that SMEs and instructors can be located literally anywhere around the globe.

\section{Concluding Comments}

Undergraduate education in digital forensics is a multidisciplinary field, combining aspects of computer and network technology, criminal justice, computer forensics, and cybercrime. Graduate level education in this field has two obvious paths -- a deeper look into the technical aspects of digital forensics and management of those engaged in digital investigations. Coupling our experience with undergraduate education in this space and our other management-related graduate programs, Champlain College elected to pursue the latter path, developing an M.S. program in Digital Investigation Management.

The key pedagogy for the M.S. program is Integrated Reflective Practice, a learning theory whereby students grasp and apply new knowledge and skills in terms of their current professional experiences. IRP is supported by a number of learning theories that all employ active learning. The essential goal is lifelong learning which is particularly important in this rapidly changing field. As Alvin Toffler observed, "The illiterate of the 21st century will not be those who cannot read and write, but those who cannot learn, unlearn, and relearn."

The M.S. DIM program will be initially available only online. The LMS that offers communication technologies that support the social aspects necessary for IRP, active learning, and social constructivism. Online education is an important vehicle for a wide variety of academic and practical disciplines; one advantage for graduate programs in an emerging field such as digital investigations is that expert instructors and practitioner students can be drawn from all over the world.

At the time of this writing, the M.S. DIM program is expected to rollout in 2009 .

\section{Acknowledgements}

The creation of the M.S. DIM program first grew out of discussions with Michael E. Schirling, Deputy Chief of the Burlington (VT) Police Department and coordinator of the Vermont Internet Crimes Task Force. The authors thank him and the other members of our Advisory Committee for their advice during the proposal process.

This work was partially supported by Grant No. 2006-DD-BX-0282 awarded by the Bureau of Justice Assistance. The Bureau of Justice Assistance is a component of the Office of Justice Programs, which also includes the Bureau of Justice Statistics, the National Institute of Justice, the Office of Juvenile Justice and Delinquency Prevention, and the Office for Victims of Crime. Points of view in this document are those of the authors and do not represent the official position of the U.S. Department of Justice. 


\section{References}

[1] Institute for Security Technology Studies (ISTS), Law Enforcement Tools and Technologies for Investigating Cyber Attacks: Gap Analysis Report. ISTS, Hanover (NH), 2004. Retrieved June 6, 2007, from http://www.ists.dartmouth.edu /TAG/gar/ISTSGapAnalysis2004.pdf

[2] H. Stambaugh, D. Beaupre, D.J. Icove, R. Baker, W. Cassaday, and W.P. Williams, State and Local Law Enforcement Needs to Combat Electronic Crime. National Institute of Justice, Research in Brief (NCJ 183451), Washington, D.C., 2000. Retrieved June 6, 2007, from http://www.ncjrs.gov/pdffiles1/nij/183451.pdf

[3] H. Stambaugh, D. Beaupre, D.J. Icove, R. Baker, W. Cassaday, and W.P. Williams, Electronic Crime Needs Assessment for State and Local Law Enforcement. National Institute of Justice, Research Report (NCJ 186276), Washington, D.C., 2001. Retrieved June 6, 2007, from http://www.ncjrs.org/pdffiles1/nij/186276.pdf

[4] National Institute of Standards and Technology (NIST), Education and Training in Digital Evidence: A Guide for Law Enforcement, Educational Institutions, and Students. Gaithersburg, MD: NIST, Technical Working Group for Education -- Digital Evidence, in press.

[5] A. Yasinsac, R.F. Erbacher, D.G. Marks, M.M. Pollitt, and P.M. Sommer, "Computer Forensics Education", IEEE Security \& Privacy, July/August 2003, pp. 15-23.

[6] P. Craiger, L. Ponte, C. Whitcomb, M. Pollitt, and R. Eaglin, "Master's Degree in Digital Forensics", Proceedings of the 40th Hawaii International Conference on Systems Sciences (HICSS 40), January 2007.

[7] Induruwa, A., "Managing the Pedagogy of Cybercrime Forensics Study at the Post Graduate Level: Challenges and Opportunities", Proceedings of CFET 2007: The 1st International Conference on Computer Forensics Education \& Training, September 2007.

[8] G.C. Kessler, "Online Education in Computer and Digital Forensics: A Case Study", Proceedings of the 40th Hawaii International Conference on Systems Sciences (HICSS 40), January 2007. Retrieved June 3, 2007, from http://www.garykessler.net/library/Online_C\&DF_education. pdf

[9] G.C. Kessler and M.E. Schirling, "The Design of an Undergraduate Degree Program in Computer \& Digital Forensics", Journal of Digital Forensics, Security, and Law, 2006 (Issue 3), pp. 37-50. Retrieved June 3, 2007 from http://www.garykessler.net/library/C\&DF_curriculum.pdf

[10] M.K. Rogers and K. Seigfried, "The Future of Computer Forensics: A Needs Analysis Survey", Computers \& Security, February 2004, pp. 12-16.
[11] M. Keeton (Ed.), The 1994 International Experiential Learning Conference, The Council for Experiential Learning, Chicago, 1994.

[12] L. Lambdin (Ed.), Roads to the Learning Society, Council for Adult and Experiential Learning, Chicago, 1991.

[13] D.C. Phillips and J.F. Soltis, Perspectives in Learning, Teachers College Press, New York, 2004.

[14] D. Douglas, "Reflections on Research Supervision: A Grounded Theory Case of Reflective Practice", Research in Post-Compulsory Education, 2003, pp. 213-229. Retrieved May 17, 2007, from taylorandfrancis.metapress.com/index /J57J1666W2340PP6.pdf

[15] P. Jarvis, The Practitioner Researcher: Developing Theory From Practice, Jossey-Bass, San Francisco, 1999.

[16] D. Boud, R. Keough, and D. Walker, Reflection, Turning Experience Into Learning, Nichols, New York, 1985.

[17] P. Cranton, In S. Imel (Ed.), Learning in Groups: Exploring Fundamental Principles, New Uses, and Emerging Opportunities, Jossey-Bass, San-Francisco, 1996.

[18] P. Senge, The Fifth Discipline: The Art and Practice of the Learning Organization, Doubleday, New York, 1990.

[19] J. Raelin, Work-based Learning: The New Frontier of Management Development, Prentice Hall, Upper Saddle River (NJ), 2000.

[20] J.A. Kuit, G. Reay, and R. Freeman, "Experiences of Reflective Teaching", Active Learning in Higher Education, December 2001, pp. 128-142.

[21] B. Dahl, "A Synthesis of Different Psychological Learning Theories? - Piaget and Vygotsky", Philosophy of Mathematics Education Journal, 2003. Retrieved June 6, 2007, from http://www.ex.ac.uk/ PErnest/pome17/pdf /bdahl.pdf

[22] M. Weller, Delivering Learning on the Net: The Why, What, \& How of Online Education. Kogan Page, London, 2002.

[23] C. Considine and T. Dean, "Active Learning in Distance Education", Proceedings of the 2003 American Society for Engineering Education Annual Conference \& Exposition. Retrieved June 6, 2007, from http://www.asee.org/acPapers /2003-1477_Final.pdf

[24] C. Meyers and T.B. Jones, Promoting Active Learning: Strategies for the College Classroom. Jossey-Bass, San Francisco, 1993.

[25] K. Alesandrini, "Visual Constructivism in Distance Learning", USDLA Journal, January 2002. Retrieved June 6, 
2007, from http://www.usdla.org/html/journal/JAN02 Issue /article03.html

[26] J.A. Donaldson and N.N. Knupfer, "Education, Learning, and Technology", In: P.L. Rogers, Designing Instruction for Technology-Enhanced Learning, Idea Group Publishing, Hershey (PA), 2002.

[27] S. Naidu, "Designing and Evaluating Instruction for ELearning", In: P.L. Rogers, Designing Instruction for Technology-Enhanced Learning, Idea Group Publishing, Hershey (PA), 2002.

[28] B.J. Duch, S.E. Groh, \& D.E. Allen (Eds.), The Power of Problem-Based Learning, Stylus Publishing, Sterling (VA), 2001.

[29] F. Bernat and C.C.I. Hall, "Teaching on the Internet: Lessons Learned From a Substantive Criminal Law Class", Journal of Criminal Justice Education, Fall 2000, pp. 295312.
[30] I.K. McKenzie, "Distance Learning for Criminal Justice Professionals in the United Kingdom: Development, Quality Assurance and Pedagogical Proprieties", Journal of Criminal Justice Education, Fall 2002, pp. 231-249.

[31] K. Swan, Relationships Between Interactions and Learning in Online Environments, The Sloan Consortium, 2004. Retrieved June 6, 2007, from http://www.sloan-c.org /publications/books/interactions.pdf

[32] D. Fabianic, "Online Instruction and Site Assessment", Journal of Criminal Justice Education, Spring 2002, pp. 173186.

[33] J. Dutton, M. Dutton, and J. Perry, "How Do Online Students Differ From Lecture Students?", Journal of Asynchronous Learning Networks, July 2002. Retrieved June 6, 2007, from http://www.sloan-c.org/publications/jaln/v6n1 /pdf/v6n1_dutton.pdf 